\title{
RBEP
}

\section{Da universalização do ensino fundamental ao desafio de democratizar o ensino médio em 2016: o que evidenciam as estatísticas?}

Leonardo Claver Amorim Lima

\section{Resumo}

O texto constitucional promulgado em 1988 prescreveu a obrigatoriedade e gratuidade do ensino fundamental, consagrando-o como um direito público subjetivo, pois inerente aos indivíduos aptos a cursá-lo. As estatísticas oficiais de matrícula e de escolarização evidenciam, com efeito, um considerável crescimento das matrículas nesse segmento da educação básica, pelo menos até meados da década de 2000. O presente artigo aborda, por meio de análise de indicadores oficiais de matrícula e escolarização, a histórica ampliação das matrículas no ensino médio no período 1990-2004 - resultante, entre outros fatores, da democratização do acesso ao ensino fundamental, iniciada e desenvolvida no mesmo período - e o desafio de universalizar sua oferta em 2016, como dispõe a Emenda Constitucional no 59, de 2009.

Palavras-chave: ensino fundamental; indicadores oficiais; ensino médio. 


\section{Abstract \\ From the elementary school universalization to the secondary school democratization in 2016: what do statistics show?}

The constitutional text promulgated in 1988 prescribed the gratuitousness and the mandatoriness of the elementary school, consecrating it as a subjective public right of the individuals who are able to attend it. The official enrollment statistics in this basic education level until the early year 2000 show an expressive growth. The present article focused on the secondary school enrollments expansion in consequence of the elementary school access democratization through the analysis of official enrollment and schooling indicators from 1990 to 2004. Moreover, the work discusses the challenge to achieve the secondary school supply universalization in 2016 as established in the Constitutional Amendment N. 59, of 2009.

Keywords: elementary school; official indicators; secondary school.

\section{Introdução}

A Constituição Federal de 1988, em seu artigo 205, consagrou a educação como um direito social cujo provimento é de responsabilidade da família e do Estado. Significa dizer que ao poder público, observados os princípios com base nos quais o ensino deve ser ministrado, compete a edição, a execução e a avaliação de políticas e diretrizes com vista à consecução dos fins que devem ser perseguidos pelo Estado em matéria educacional.

A materialização do direito social à educação no Brasil pressupõe, assim, uma efetiva atuação estatal, como leciona Carneiro (2010, p. 42):

no caso da educação, a ação concreta do Estado está desdobrada em uma ampla gama de obrigações irrenunciáveis, tidas como competências do Estado brasileiro e face ao não cumprimento das quais cabem mecanismos de acionabilidade jurídica, ou seja, de responsabilização criminal.

A mera enunciação no texto constitucional do direito à educação não é, pois, suficiente para garantir sua consecução. Em verdade, às normas definidoras de tal direito social devem corresponder mecanismos - garantias - por meio dos quais seus titulares possam fazê-lo valer em caso de omissão ou inadequada prestação por parte do Estado.

O artigo 208 da Constituição vigente enuncia, sob essa ótica, as garantias mediante as quais o dever do Estado com a educação será 
efetivado. Já o inciso I desse artigo, ao assegurar a obrigatoriedade e a gratuidade do ensino fundamental e sua oferta inclusive aos que a ele não tiveram acesso na idade própria, evidenciou, à época da promulgação da Constituição, a centralidade da política educacional editada pelo legislador constituinte na universalização do acesso a esse nível educacional.

Tal centralidade é indicada, além disso, pela estrutura do financiamento da educação estatuída pela redação original da Carta Magna. Por isso mesmo, o artigo 60 do Ato das Disposições Constitucionais Transitórias (ADCT) determinou que, nos dez primeiros anos da promulgação da Constituição, o poder público destinasse, pelo menos, cinquenta por cento dos recursos já vinculados à educação por força do artigo $212^{1}$ para, além de erradicar o analfabetismo, universalizar o acesso ao ensino fundamental. Além disso, no texto constitucional originário, a contribuição social do salário-educação alcançava exclusivamente a escola fundamental. Também, com o expresso fim de universalizar o ensino fundamental, foi instituído - nos termos da Emenda Constitucional $n^{\circ} 14$, de 1996, que alterou a redação do artigo 60 do ADCT - o Fundo de Manutenção e Desenvolvimento do Ensino Fundamental e de Valorização do Magistério (Fundef).

Ressalte-se ainda que o primeiro Plano Nacional de Educação (PNE 2001-2010 - Lei no 10.172, de 9 de janeiro de 2001) estabeleceu como meta a ser atingida no prazo de cinco anos, contados de sua vigência,

[...] o atendimento de toda a clientela do ensino fundamental [...], garantindo o acesso e a permanência de todas as crianças na escola, estabelecendo em regiões em que se demonstrar necessário programas específicos, com a colaboração da União, dos Estados e dos Municípios.

Vale dizer que, em 2006, ano subsequente ao estipulado para a consecução da referida meta do PNE e prazo final de vigência do Fundef, dados do Censo Escolar realizado pelo Instituto Nacional de Estudos e Pesquisas Educacionais Anísio Teixeira (Inep) apontavam que a pretendida universalização do acesso ao ensino fundamental fora praticamente alcançada, tendo em vista que 97,7\% das crianças de 7 a 14 anos de idade estavam matriculadas no sistema de ensino.

Nesse cenário, a Emenda Constitucional nº 53, de 2006, instituiu, no âmbito de cada Estado e do Distrito Federal, um fundo de natureza contábil destinado ao financiamento de toda a educação básica - o Fundo de Manutenção e Desenvolvimento da Educação Básica e de Valorização dos Profissionais da Educação (Fundeb). Além disso, estatuiu que a contribuição social do salário-educação, antes voltada unicamente ao ensino fundamental, constitui fonte de financiamento também do ensino médio.

Portanto, embora não inteiramente concluído, o processo de democratização do acesso ao ensino fundamental suscitou a atenção do poder público para a necessidade de ampliação das oportunidades educacionais dos egressos desse segmento da educação básica.
${ }^{1}$ Determina que a União aplique nunca menos de $18 \%$ e os Estados, o Distrito Federal e os Municípios não menos de $24 \%$ das receitas resultantes de impostos na manutenção e desenvolvimento do ensino. 
${ }^{2}$ A idade própria para o acesso ao ensino fundamental é disciplinada pela Lei de Diretrizes e Bases da Educação Nacional (Lei no 9.394/96), art. 32, na forma da Lei $\mathrm{n}^{\circ} 11.274$, de 6 de fevereiro de 2006 .

${ }^{3}$ Os dados de matrículas (inclusive as definições de taxas de matrícula e de taxa de frequência à escola) constantes deste ensaio foram obtidos por meio de consulta à Diretoria de Estatísticas Educacionais do Inep, e os dados censitários, junto aos estabelecimentos escolares. Até o ano de 2006, a data de referência do Censo era a última quarta-feira do mês de março do respectivo ano; a partir de 2007, nos termos da Portaria no 264/2007 do Ministério da Educação, a referência passou a ser a última quarta-feira do mês de maio.

${ }^{4}$ Comparações entre o tamanho da população de uma faixa etária e as matrículas de indivíduos desta devem observar a diferença da fonte e das metodologias das respectivas pesquisas. As informações acerca de tamanho de população constantes deste trabalho provêm das Pesquisas Nacionais por Amostra de Domicílio (Pnads) da Fundação IBGE (com exceção dos anos de 1991 e 2000, em que os dados são do Censo Demográfico, também do IBGE). Diferentemente do Censo Escolar do Inep, as pesquisas do IBGE são feitas em domicílios, no mês de setembro de cada ano, e, assim, desencontros entre as duas variáveis são esperados. E o que se observa, sobretudo, no cálculo da TML.
Com o advento da Emenda Constitucional n 59, de 11 de novembro de 2009, estatuiu-se, nos termos do inciso I do art. 208 da Carta Magna, a obrigatoriedade e gratuidade, a partir do ano de 2016, da educação básica dos 4 aos 17 anos de idade, assegurada sua oferta gratuita inclusive aos indivíduos que a ela não tiveram acesso em tal faixa etária.

Assim, além da escolarização relativa à faixa etária de 4 a 5 anos de idade e do ensino fundamental ${ }^{2}$ (dos 6 aos 14), o acesso ao ensino médio, quer na idade própria (dos 15 aos 17 anos), quer fora dela, passa a constituir um direito público subjetivo amparado pela Lei Maior. Com efeito, aos indivíduos aptos a cursá-lo é atribuída a prerrogativa de exigir do poder público sua oferta gratuita.

Nesse contexto, o presente artigo aborda o processo de crescimento quantitativo do ensino fundamental, iniciado e desenvolvido especialmente na década de 1990, do qual decorreu um inédito incremento, também em termos quantitativos, do ensino médio, pelo menos até meados da década de 2000. Com base em análise (quando esta for possível) da atual capacidade de atendimento da escola média brasileira, discute-se o desafio de democratizá-la até o ano de 2016, como preconiza a EC n 59/2009.

\section{A universalização do ensino fundamental}

Gomes (2001), em pesquisa acerca da democratização do ensino médio, afirma que a década de 1990 tem legado importantes avanços, pelo menos de ordem quantitativa, na educação brasileira.

Quanto ao ensino fundamental regular, conforme as estatísticas oficiais apresentadas na Tabela 1, foram registrados ${ }^{3}$ 29,2 milhões de matrículas no ano de 1991. Se os dados brutos não permitem grandes conclusões, o confronto ${ }^{4}$ destes com o tamanho da população na faixa etária de 7 a 14 anos - considerada a idade adequada para o ensino fundamental à época (27,5 milhões) - traz maior clareza à análise: observa-se que já no início da década de 1990 a rede de ensino fundamental apresentava, em tese, condições de atender a todos os indivíduos em idade própria para a escolarização obrigatória.

Entretanto, como condições de atendimento não asseguram oportunidades escolares aos discentes de um nível educacional e tampouco informam sobre a distribuição das matrículas por faixa etária, as pesquisas oficiais se valem de alguns indicadores para vencer tais limitações. Assim é que:

- A Taxa de Matrícula Líquida (TML) é um indicador que identifica o percentual da população em determinada faixa etária matriculada no nível de ensino adequado a essa faixa etária.

- A Taxa de Matrícula Bruta (TMB) é um indicador que permite comparar o total de matrículas de determinado nível de ensino com a população na faixa etária adequada a esse nível de ensino. 
- A Taxa de Frequência à Escola (TF) é um indicador que permite avaliar o acesso da população ao sistema educacional. É o percentual da população de uma faixa etária que frequenta a escola independentemente de nível/modalidade de ensino.

Os dados censitários do Inep (Tabela 1) indicam que, do total de matrículas registradas no ensino fundamental em 1991, 23,7 milhões correspondem a indivíduos na faixa etária de 7 a 14 anos e 4,7 milhões, a indivíduos com mais de 14 anos. Assim, nesse ano, a TMB no ensino fundamental era de aproximadamente 106\%, enquanto a TML era de 81\%. Se, como afirma Oliveira (2007), quão mais próximas estiverem, simultaneamente, as taxas de matrícula bruta e líquida, maior será a efetividade do sistema educacional. A realidade do ensino fundamental no início da última década do século 20, em que pesem os inegáveis avanços quantitativos em relação às décadas precedentes, revelava-se preocupante. Além disso, considerada a diferença entre o tamanho da população em idade própria para o ensino fundamental e o quantitativo de matrículas associadas à faixa etária recomendada, mais de 3 milhões de crianças de 7 a 14 anos de idade estavam fora da escola. No início da década de 1990, portanto, o sistema de ensino fundamental brasileiro via-se diante de um paradoxo: apresentava condições físicas - capacidade instalada - de atender a todos os indivíduos na faixa etária adequada, mas, dado o considerável número de indivíduos fora da faixa etária na escola e de indivíduos em idade própria fora dela, não o fazia.

A análise dos dados apresentados na Tabela 1, considerando-se, também, os anos de 1994, 1996 e 1999, permite uma visão mais ampla da distribuição de matrículas por faixa etária e, com efeito, da efetividade do ensino fundamental na década de 1990.

Observa-se que, entre 1994 e 1999, houve um incremento de 4,1 milhões de matrículas no ensino obrigatório. Não parece razoável atribuir esse acréscimo a variações no tamanho da população de 7 a 14 anos no período; pelo contrário, observa-se que este teve uma considerável diminuição (de 28,9 milhões de indivíduos em 1994 para 25,1 milhões em 1999). Também é verdade que, entre 1991 e 1999, embora tenham sido realizadas 6,8 milhões de novas matrículas, o número de indivíduos na população de 7 a 14 anos teve decréscimo (menos 2,4 milhões). Assim, as duas primeiras variáveis consideradas parecem caminhar para lados opostos.

A participação relativa das matrículas de indivíduos na faixa etária recomendada para a escola fundamental regular, isto é, a relação entre essa variável e o total das matriculas, mostrou-se abaixo de $80 \%$ em três dos quatro momentos considerados. A exceção foi observada no ano de 1991, no qual 81\% das matrículas são associadas a indivíduos de 7 a 14 anos. Em 1994, 1996 e 1999 as estatísticas eram, respectivamente, 
79\%, 78\% e 74\%. Assim, apesar do aumento absoluto dessa variável (um incremento de 0,56 milhão de matrículas de 1994 para 1996, de 1,1 milhão de matrículas de 1996 para 1999, de 1,67 milhão de matrículas de 1994 para 1999 e de 3,2 milhões de matrículas de 1991 para 1999), sua participação relativa na composição do quantitativo total de matrículas se mostrou decrescente. O aumento das matrículas na faixa própria contribuiu, entretanto, para uma considerável ampliação do atendimento educacional fundamental na idade própria em 1999 (TML de $90,6 \%$ e TF de 95,7\%).

Chama a atenção o fato de que a variável matrícula de indivíduos maiores de 14 anos parece ser, entre as aqui analisadas, a que melhor se associa, em termos absolutos e relativos, ao crescimento das matrículas no ensino fundamental na década de 1990 - no caso, considerados os anos de 1991, 1994, 1996 e 1999, conforme a Tabela 1:

- Em 1991, a participação relativa dos indivíduos nessa faixa etária nas matrículas era de 16\% e, em 1994, de 18\%. O aumento absoluto das matrículas nesse período foi de 1,01 milhão;

- Entre 1994 e 1996, 1,1 milhão de novas matrículas correspondentes a essa faixa etária foram realizadas, e a participação relativa no último ano foi de 20,7\%;

- De 1996 a 1999, enquanto mais 1,6 milhão de indivíduos com idade superior a 14 anos se matricularam nas redes de ensino fundamental, a participação relativa dessas matrículas em 1999 foi de aproximadamente 23\%;

- Considerando-se o período 1991-1999, o crescimento das matrículas nessa faixa etária foi de 3,7 milhões.

Tendo em vista o número irrisório de indivíduos menores de 7 anos e a significativa participação de maiores de 14 anos - especialmente na faixa de 15 a 17 anos - na composição das matrículas na década de 1990, o ensino fundamental brasileiro demonstrou, como já observou Oliveira (2007), uma inédita capacidade de absorver adolescentes e adultos, notadamente os que deveriam estar cursando o ensino médio.

Por isso mesmo, a TMB atingiu seu pico em 1999 (TMB $=143 \%$, conforme a Tabela 1), o que indica um grave problema de distorção idade-série na escola fundamental regular, uma vez que pouco mais de 90\% (TML = 90,6\%) da população em idade própria encontrava-se matriculada. Com efeito, no ano 2000, dos 35,7 milhões de registros escolares, apenas 26,8 milhões estavam associados a indivíduos na idade adequada. Ressalte-se que, no mesmo ano, das matrículas fora da faixa de 7 a 14 anos (8,8 milhões) 5 , 5,4 milhões (60\%) foram realizadas por

${ }^{5}$ Incluídas as de crianças com idade inferior a 7 anos: 0,5 milhão. indivíduos com idades entre 15 e 17 anos. Portanto, também aqui fica evidente a considerável presença de discentes (mais de 5 milhões) na faixa etária ideal para o ensino médio. 
Tabela 1 - População na faixa etária de 7 a 14 anos, matrículas no ensino fundamental por faixa etária e indicadores oficiais de matrícula e de escolarização - 1991/2009

\begin{tabular}{|c|c|c|c|c|c|c|c|}
\hline Ano & $\begin{array}{c}\text { Pop. de 7 a } \\
\text { 14 anos }\end{array}$ & $\begin{array}{c}\text { Total de } \\
\text { matrículas }\end{array}$ & $\begin{array}{c}\text { Matr. de 7 } \\
\text { a 14 anos }\end{array}$ & $\begin{array}{c}\text { Mais. de } \\
\text { manos }\end{array}$ & $\begin{array}{c}\text { TMB } \\
\mathbf{( \% )}\end{array}$ & $\begin{array}{c}\text { TF } \\
\mathbf{( \% )}\end{array}$ & $\begin{array}{c}\text { TML } \\
\mathbf{( \% )}\end{array}$ \\
\hline 1991 & 27.509 .324 & 29.203 .724 & 23.777 .418 & 4.760 .693 & 106,0 & $\ldots$ & 81,0 \\
\hline 1994 & 28.931 .666 & 31.910 .974 & 25.349 .862 & 5.777 .916 & 110,0 & $\ldots$ & $\ldots$ \\
\hline 1996 & 28.525 .815 & 33.131 .270 & 25.909 .860 & 6.879 .034 & 116,0 & 91,3 & $\ldots$ \\
\hline 1999 & 25.105 .782 & 36.059 .742 & 27.016 .884 & 8.473 .978 & 143,0 & 95,7 & 90,6 \\
\hline 2000 & 27.124 .709 & 35.717 .948 & 26.840 .815 & 8.384 .001 & 131,0 & 94,5 & 90,3 \\
\hline 2001 & 26.101 .895 & 35.298 .089 & 26.820 .814 & 7.955 .208 & 135,2 & 96,5 & 93,1 \\
\hline 2002 & 26.414 .399 & 35.150 .362 & 27.040 .644 & 7.577 .784 & 134,6 & 96,9 & 93,7 \\
\hline 2003 & 26.266 .814 & 34.438 .749 & 27.061 .394 & 6.852 .788 & 131,0 & 97,2 & 93,8 \\
\hline 2004 & 27.629 .064 & 34.012 .434 & 27.070 .511 & 6.219 .325 & 123,0 & 97,1 & 93,8 \\
\hline 2005 & 27.478 .129 & 33.534 .561 & 27.063 .256 & 5.705 .496 & 117,0 & 97,4 & 94,4 \\
\hline 2006 & 27.948 .583 & 33.282 .663 & 27.127 .536 & 5.253 .830 & 122,0 & 97,7 & 94,8 \\
\hline 2007 & 28.318 .829 & 32.122 .273 & 27.044 .577 & 4.666 .269 & 112,0 & 97,7 & 94,6 \\
\hline 2009 & 27.502 .966 & 32.086 .700 & 27.016 .884 & 3.693 .714 & 115,0 & 98,0 & 94,9 \\
\hline & $\ldots$ & 31.705 .528 & 27.600 .748 & 3.883 .329 & $\ldots$ & 98,1 & $\ldots$ \\
\hline
\end{tabular}

Fontes: MEC/Inep/Deed, 2010; Fundação IBGE, 2010.

Observação: Para o cálculo da TMB, observou-se a razão, em um mesmo ano, entre o total de matrículas e o tamanho da população na faixa etária própria para o ensino fundamental.

A diminuição de 12 pontos percentuais na TMB do ano 2000 (131\%), ilustrada na Tabela 1, dava sinais de uma espetacular melhora da efetividade do ensino fundamental, mas a análise dos dados agregados permite sua relativização. Ora, entre 2001 e 2002, o número de matrículas teve ligeira variação (menos 0,14 milhão), o mesmo sendo observado com as matrículas na idade própria. Já as matrículas de jovens maiores de 14 anos, embora ainda consideráveis, diminuíram, dando início ao processo de redução de sua participação relativa na composição dos registros escolares nos anos subsequentes. Assim, houve, de um ano para o outro, uma significativa melhora da movimentação escolar no ensino fundamental em decorrência do processo de regularização do fluxo iniciado e desenvolvido especialmente no final dos anos 1990. Por isso mesmo, enquanto o número de matrículas entre 1994 e 2001 aumentou 10\%, o número de concluintes entre 1995 e 2002 cresceu 61\%. 
As taxas de matrícula líquida e de frequência à escola (TML e TF) apresentaram crescimento entre 2003 e 2008, ano a ano, conforme a Tabela 1. A TMB, por seu turno, diminuiu em praticamente todos os interstícios do período, o que revela que, embora em ritmo lento, a participação relativa de indivíduos fora da idade própria para o ensino fundamental nas matrículas está decrescendo.

Em 2008, 97,5 \% das crianças de 6 a 14 anos e 98\% das de 7 a 14 anos estavam matriculadas na escola (TF). No caso, a TML era de 94,9\%. A TMB, de 115\% (variação de três pontos percentuais em relação a 2007), confirma a tendência de diminuição gradual da população fora da faixa etária própria nas redes de ensino fundamental. Os levantamentos ${ }^{6}$ demográficos do IBGE de 2009 apontam crescimento de 0,1\% na $\mathrm{TF}^{7}$ tanto das crianças de 6 a 14 anos quanto das de 7 a 14 anos de idade. Os dados são, respectivamente, 97,6\% e 98,1\%.

Portanto, se a igualdade entre as taxas de matrícula bruta e líquida no ensino fundamental regular, que representaria o atendimento de toda a população na idade própria e na série adequada, está longe de ser alcançada, não se pode negar que o acesso é praticamente universal.

\section{O desafio de democratizar o ensino médio}

O processo de universalização do acesso ao ensino fundamental na década de 1990 representa inegável avanço na história educacional brasileira. Sem que a questão da qualidade da educação seja trazida à discussão, uma quantidade não desprezível de indivíduos (quer na idade própria, quer fora dela) teve acesso aos bancos escolares. Além disso, a melhoria do fluxo escolar dos alunos e o aumento do número de concluintes são evidentes.

Com efeito, como já observaram Gomes (2001), Oliveira (2007) e Sampaio (2007), o número de matrículas no ensino médio, etapa da educação básica subsequente ao ensino fundamental, teve considerável aumento nessa década.

\section{O ensino médio na década de 1990}

${ }^{6}$ Pesquisa Nacional por Amostra de Domicílios de 2009 (Pnad/2009)

7 Aqui, deve-se observar que o Inep e o IBGE usam nomenclaturas distintas para o indicador que identifica o percentual da população numa faixa etária que está matriculada na escola independentemente do nível ou modalidade de ensino: enquanto para o Inep o indicador é a "taxa de frequência à escola" (TF), nas pesquisas do IBGE o indicador é chamado de "taxa de escolarização".
Os dados constantes das Tabelas 2 e 3 indicam que em 1991 foram registrados 3,7 milhões de matrículas no ensino médio regular. A comparação com a população de 15 a 17 anos, faixa etária apropriada para tal nível educacional, no mesmo ano (mais de 9 milhões de indivíduos), por si, já não é animadora. Mas é a distribuição das matrículas por faixa etária, apresentada na Tabela 3, que permite uma melhor análise da situação da escola média no início da década de 1990: enquanto aproximadamente 2 milhões de registros escolares correspondem a indivíduos maiores de 17 anos de idade, apenas 1,6 milhão foram realizados por indivíduos em idade própria. Assim, nesse ano, a TMB no ensino médio era de apenas $33,3 \%$, e a TML, por seu turno, de $14,3 \%$. 
Portanto, enquanto o sistema de ensino fundamental possuía capacidade instalada para atender todo o seu efetivo discente na faixa etária adequada, o de ensino médio estava distante de abrigar a metade (TMB de 33\%) da população na idade recomendada. Além disso, pouco mais de 14\% (TML de 14,3\%) dos indivíduos de 15 a 17 anos estavam cursando alguma série ou ciclo do ensino médio. Por consequência, a democratização do acesso a esse nível de ensino se mostrava distante.

Em 1993, as matrículas somaram 4,5 milhões. Assim, entre 1991 e 1993, houve um aumento de 18\% no total de registros. Chama a atenção o fato de que, entre 1990 e 1992, o número de concluintes do ensino fundamental (Tabela 2) teve, em termos relativos, um incremento praticamente idêntico (cresceu 18,6\%). Além disso, o crescimento das matrículas na $1^{\mathrm{a}}$ serie da escolarização média entre 1991 e 1993 foi de 18\%.

Ora, se aos concluintes do ensino fundamental que desejem prosseguir os estudos na escola regular resta, a princípio, o ingresso na $1^{\text {a }}$ série do ensino médio no ano subsequente, parece razoável que o aumento das matrículas neste nível de ensino encontre certa explicação - embora não se trate de uma relação determinística, isto é, nem todos os que concluem o ensino fundamental ingressam, no ano seguinte, no ensino médio - no aumento do número de concluintes da escolarização fundamental.

Tabela 2 - Concluintes do ensino fundamental, distribuição de matrículas por série no ensino médio e concluintes do ensino médio - 1990-99

\begin{tabular}{|c|c|c|c|c|c|c|}
\hline Ano & $\begin{array}{c}\text { Concluintes } \\
\text { do EF }\end{array}$ & $\begin{array}{c}\text { Matr. 1 } \\
\text { série do } \\
\text { EM }\end{array}$ & $\begin{array}{c}\text { Matr. 2 } \\
\text { série do } \\
\text { EM }\end{array}$ & $\begin{array}{c}\text { Matr. } \mathbf{3}^{\mathbf{a}} \\
\text { série do } \\
\text { EM }\end{array}$ & $\begin{array}{c}\text { Matr. } \\
\text { no EM } \\
\text { (Total) }\end{array}$ & $\begin{array}{c}\text { Concluintes } \\
\text { do EM }\end{array}$ \\
\hline 1990 & 1.065 .970 & $\ldots$ & $\ldots$ & $\ldots$ & $\ldots$ & 639.008 \\
\hline 1991 & 1.113 .246 & 1.708 .196 & 1.112 .311 & 801.731 & 3.772 .698 & 666.367 \\
\hline 1992 & 1.264 .846 & 1.861 .341 & 1.218 .852 & 858.265 & 4.104 .643 & 721.857 \\
\hline 1993 & 1.400 .381 & 2.014 .786 & 1.343 .565 & 947.044 & 4.478 .631 & 817.556 \\
\hline 1994 & 1.588 .631 & 2.188 .133 & 1.492 .303 & 1.065 .640 & 4.932 .225 & 917.298 \\
\hline 1995 & 1.720 .540 & 2.364 .864 & 1.627 .060 & 1.182 .384 & 5.374 .831 & 959.545 \\
\hline 1996 & 1.923 .762 & 2.527 .580 & 1.727 .171 & 1.274 .933 & 5.739 .007 & 1.163 .788 \\
\hline 1997 & 2.151 .835 & 2.765 .260 & 1.962 .640 & 1.445 .046 & 6.405 .057 & 1.330 .150 \\
\hline 1998 & 2.383 .207 & 2.900 .429 & 2.164 .831 & 1.663 .073 & 6.968 .531 & 1.535 .943 \\
\hline 2.484 .972 & 3.195 .758 & 2.418 .473 & 1.884 .854 & 7.769 .199 & 1.786 .827 \\
\hline
\end{tabular}

Fonte: MEC/Inep/Deed, 2010.

Observação: $\mathrm{EF}=$ ensino fundamental regular; $\mathrm{EM}$ = ensino médio regular. 
O aumento das matrículas no ensino médio na década foi superior, em termos absolutos e relativos, a variações no tamanho da população na faixa etária de 15 a 17 anos, como ilustram os dados da Tabela 3. No caso, enquanto em 1991 essa população somava pouco mais de 9 milhões de indivíduos, em 2000 eram 10,7 milhões de indivíduos na faixa etária. Assim, caso exista, a relação entre o crescimento da população na idade própria e o das matrículas no ensino médio nos anos 1990 não se mostra significativa.

A participação relativa das matrículas realizadas por indivíduos de 15 a 17 anos no total de registros não sofreu alterações significativas entre 1991 e 1999. Em 1994, 44\% das matrículas estão associadas à população na idade própria, ${ }^{8}$ enquanto 53\% correspondem a maiores de 17 anos; em 1999, os dados relativos das mesmas variáveis são, respectivamente, $43 \%$ e $55 \%$. No mesmo período, as matrículas realizadas por jovens com idade superior a 17 anos tiveram crescimento absoluto de 1,7 milhão de registros. Aqui, dada a grande quantidade de jovens que foram absorvidos pelo ensino fundamental nos anos 1990, é possível que estes, com o contemporâneo aumento do número de concluintes do ensino obrigatório, tenham ingressado na escola média já com idade defasada. Em outros termos, ao aumento das matrículas não correspondeu uma maior participação relativa de indivíduos na idade própria para o ensino médio.

\section{Tabela 3 - Distribuição de matrículas no ensino médio por faixa etária e indicadores de matrícula e escolarização para a idade própria do ensino médio -1991/99}

\begin{tabular}{|c|c|c|c|c|c|c|c|c|c|}
\hline Ano & $\begin{array}{l}\text { Pop. de } 15 \\
\text { a } 17 \text { anos }\end{array}$ & $\begin{array}{c}\text { Total de } \\
\text { matrículas }\end{array}$ & $\begin{array}{c}\text { Matr. de } \\
15 \text { a } 17 \\
\text { anos }\end{array}$ & $\begin{array}{l}\text { Matr. de } \\
\text { mais de } \\
17 \text { anos }\end{array}$ & $\begin{array}{c}\text { Matr. } \\
\text { de } 15 \\
\text { a } 17 \\
\text { anos } \\
(\%)\end{array}$ & $\begin{array}{c}\text { Matr. } \\
\text { de } \\
\text { mais } \\
\text { de } 17 \\
\text { anos } \\
(\%)\end{array}$ & $\begin{array}{l}\text { TML } \\
(\%)\end{array}$ & $\begin{array}{c}\text { TMB } \\
(\%)\end{array}$ & $\begin{array}{l}\text { TF } \\
(\%)\end{array}$ \\
\hline 1991 & 9.275 .706 & 3.772 .698 & 1.626 .570 & 2.017.289 & 43,1 & 53,5 & 14,3 & 33,3 & 58,1 \\
\hline 1994 & $\ldots$ & 4.932 .552 & 2.157 .663 & 2.608.007 & 43,7 & 52,9 & 22,7 & 51,6 & $\ldots$ \\
\hline 1995 & 10.163 .417 & 5.374 .831 & 2.388 .403 & 2.804 .251 & 44,5 & 52,1 & 23,5 & 53,5 & 66,6 \\
\hline 1996 & 10.349.696 & 5.739 .077 & 2.525 .326 & 3.114 .335 & 44,0 & 54,2 & 24,4 & 55,3 & 69,5 \\
\hline 1998 & 10.130 .470 & 6.968 .531 & 3.120 .185 & 3.751 .872 & 44,7 & 53,8 & 30,8 & 68,1 & 76,5 \\
\hline 1999 & 10.395 .438 & 7.769 .199 & 3.388 .913 & 4.290 .083 & 43,6 & 55,2 & 32,6 & 74,8 & 78,5 \\
\hline
\end{tabular}

Fontes: MEC/Inep/Deed, no caso das matrículas e taxas de escolarização, e IBGE, para os dados populacionais.

${ }^{8}$ Desprezadas as matrículas realizadas por menores de 15 anos.
Entretanto, tendo em vista os dados apresentados na Tabela 3, cabe destacar que o incremento absoluto de matrículas de indivíduos fora da idade própria contribuiu para um significativo aumento da TMB do ensino médio na década (de 33,3\% em 1991 para 74,8\% em 1999). As redes de ensino médio atendiam, portanto, no final dos anos 1990, um número de discentes correspondente a quase $75 \%$ da população de 15 a 17 anos (aproximadamente 7,7 milhões de indivíduos). O aumento absoluto das 
matrículas realizadas na idade própria (mais de 1,7 milhão de matrículas entre 1991 e 1999), observado em todos os períodos, contribuiu, por seu turno, para que a TML mais que dobrasse na década (de 14\% em 1991 para 32\% em 1999). Em outros termos, a razão entre o número de pessoas de 15 a 17 anos que frequentavam a escola média e o total da população nessa faixa etária teve acréscimo significativo no período.

Não obstante, em 1999, dos 10,3 milhões de indivíduos com idades entre 15 e 17 anos (Tabela 3), apenas 3,3 milhões estavam matriculados no ensino médio. Chama a atenção o fato de que, no mesmo ano, a TF dos indivíduos na faixa etária era de 78,5\% (em termos absolutos, mais de 8 milhões de indivíduos). Nesse contexto, fica evidente que muitos jovens que deveriam estar cursando o ensino médio ainda estavam no ensino fundamental (se mais de 8 milhões de pessoas na faixa etária frequentavam a escola e, destas, pouco mais de 3.000.000 no ensino médio, resta considerar que a grande maioria dos demais indivíduos ainda cursavam alguma série do ensino obrigatório).

Vale destacar que a distribuição das matrículas entre as três séries do ensino médio se mostrou heterogênea, com forte concentração na série inicial, como evidenciam os dados da Tabela 4. Em praticamente todos os períodos considerados, o percentual das matrículas na $1^{\mathrm{a}}$ série foi superior a 43\%, na $2^{\mathrm{a}}$ série oscilou entre $29 \%$ e $31 \%$ e, na 3a, manteve-se abaixo de $25 \%$. Assim, apesar da melhoria do fluxo observada em 1999, a movimentação escolar revelou-se bastante irregular - como observa Oliveira (2007), o fluxo ótimo num sistema educacional seriado é aquele em que as matrículas estão uniformemente (ou algo próximo disso) divididas entre suas séries/ciclos/etapas.

\section{Tabela 4 - Distribuição de matrículas por série no ensino médio regular - 1991/99}

\begin{tabular}{|c|c|c|c|}
\hline Ano & $\begin{array}{r}\text { Matr. } \mathbf{1}^{\mathbf{a}} \text { série do } \\
\text { EM (\%) }\end{array}$ & $\begin{array}{c}\text { Matr. } \mathbf{2}^{\mathbf{a}} \text { série do } \\
\text { EM (\%) }\end{array}$ & $\begin{array}{c}\text { Matr. } \text { 3 }^{\mathbf{a}} \text { série do } \\
\text { EM (\%) }\end{array}$ \\
\hline 1991 & 45,7 & 29,4 & 21,2 \\
\hline 1993 & 45,0 & 29,9 & 21,1 \\
\hline 1995 & 44,0 & 30,2 & 21,9 \\
\hline 1997 & 43,1 & 30,6 & 22,5 \\
\hline 1999 & 41,1 & 31,1 & 24,2 \\
\hline
\end{tabular}

Fonte: MEC/Inep/Deed, 2010.

Observação: não foram consideradas as matrículas da $4^{\circ}$ série do ensino médio e do ensino médio não seriado.

O confronto entre o número de matrículas na $1^{\mathrm{a}}$ série computadas num ano, apresentado na Tabela 2, e o de concluintes após três anos em qualquer interstício da década de 1990 revela que muitos discentes não tiveram um adequado aproveitamento dos estudos ou foram afastados do sistema por abandono. Assim, enquanto em 1991 houve 1,7 milhão de matrículas na $1^{\text {a }}$ série, o número de concluintes em 1994 somou apenas 0,9 milhão. Já em 1996 foram 2,5 milhões de matrículas na série inicial, ao passo que o número de concluintes apurado pelo Censo Escolar do Inep em 1999 foi de apenas 1,7 milhão. 
Portanto, apesar do crescimento de matrículas sem precedentes na história educacional brasileira, a situação do ensino médio no final da década de 1990 denotava um grande desafio a ser materializado com vista à democratização de seu acesso na década subsequente.

\section{O ensino médio nos anos 2000}

Os 8,1 milhões de matrículas realizadas no ensino médio regular no ano 2000 (Tabela 5), 0,4 milhão a mais (5\%) em relação ao ano anterior, sinalizavam que o acesso à última etapa da educação básica continuaria a se expandir. Se a TML era de apenas 34\%, a grande quantidade de egressos do ensino fundamental com idades entre 14 e 16 anos (por isso que a TF dos indivíduos em idade própria para a escolarização média, de 77\%, era muito superior à correspondente TML) trazia expectativas de uma maior participação dos indivíduos em idade própria. A TMB, por seu turno, evidenciava que o sistema já possuía capacidade instalada para atender $73 \%$ da população de 15 a 17 anos, que era de aproximadamente 10,7 milhões de indivíduos.

Tabela 5 - População de 15 a 17 anos, distribuição das matrículas no ensino médio regular e indicadores de matrícula e escolarização - 2000-09

\begin{tabular}{|l|l|l|l|c|c|c|c|}
\hline Ano & $\begin{array}{c}\text { Pop. de 15 a } \\
\text { 17 Anos }\end{array}$ & $\begin{array}{c}\text { Total de } \\
\text { Matrículas }\end{array}$ & $\begin{array}{c}\text { Matr. de } \\
\mathbf{1 5} \text { a 17 } \\
\text { Anos }\end{array}$ & $\begin{array}{c}\text { Matr. de } \\
\text { mais de 17 } \\
\text { Anos }\end{array}$ & $\begin{array}{c}\text { TMB } \\
\mathbf{( \% )}\end{array}$ & $\begin{array}{c}\text { TF } \\
\mathbf{( \% )}\end{array}$ & $\begin{array}{c}\text { TML } \\
\mathbf{( \% )}\end{array}$ \\
\hline 2000 & 10.702 .499 & 8.192 .948 & 3.565 .240 & 4.561 .998 & 73,0 & $\mathbf{7 7 , 7}$ & 34,4 \\
\hline 2001 & 10.308 .707 & 8.398 .008 & 3.817 .382 & 4.515 .144 & 73,9 & 81,1 & 36,9 \\
\hline 2002 & 10.357 .443 & 8.710 .584 & 4.161 .691 & 4.477 .850 & 75,9 & 81,5 & 40,0 \\
\hline 2003 & 10.481 .393 & 9.072 .972 & 4.470 .266 & 4.529 .516 & 81,1 & 82,4 & 43,1 \\
\hline 2004 & 10.742 .044 & 9.169 .357 & 4.660 .419 & 4.444 .228 & 81,4 & 81,9 & 44,4 \\
\hline 2005 & 10.646 .814 & 9.301 .302 & 4.687 .574 & 4.261 .841 & 80,7 & 81,7 & 45,3 \\
\hline 2006 & 10.424 .755 & 8.906 .820 & 4.723 .399 & 4.093 .549 & 82,2 & 82,2 & 47,1 \\
\hline 2007 & 10.262 .468 & 8.369 .369 & 4.539 .022 & 3.643 .528 & 82,6 & 82,1 & 48,0 \\
\hline 2008 & 10.289 .624 & 8.272 .159 & 5.222 .019 & 2.956 .670 & 85,5 & 84,1 & 50,4 \\
\hline 2009 & $\ldots$ & 8.337 .160 & 5.175 .582 & 3.010 .504 & $\ldots$ & $\ldots$ & $\ldots$ \\
\hline
\end{tabular}

Fontes: MEC/Inep/Deed, 2010; Fundação IBGE, 2010.

Em 2002, as matrículas na escola média somaram 8,7 milhões. Logo, entre 2000 e 2002, o crescimento absoluto foi de aproximadamente 0,5 milhão. É interessante notar que, de 1999 para 2001, o número de concluintes do ensino fundamental, que teve um incremento de mais de 100\% na década de 1990, diminuiu significativamente: de 2,4 milhões em 1999 para 1,8 milhão em 2001. Aqui, portanto, não parece razoável atribuir o acréscimo nas matrículas a variações no número de concluintes do ensino fundamental. 
Tabela 6 - Concluintes do ensino fundamental e do ensino médio e distribuição absoluta de matrículas por série no ensino médio - 2000-09

\begin{tabular}{|l|l|l|l|l|l|}
\hline Ano & $\begin{array}{c}\text { Concluintes } \\
\text { do EF }\end{array}$ & $\begin{array}{c}\text { Matr. } \mathbf{1}^{\mathbf{a}} \text { sé- } \\
\text { rie do EM }\end{array}$ & $\begin{array}{c}\text { Matr. } \mathbf{2}^{\mathrm{a}} \text { sé- } \\
\text { rie do EM }\end{array}$ & $\begin{array}{c}\text { Matr. } \mathbf{3}^{\mathbf{a}} \text { sé- } \\
\text { rie do EM }\end{array}$ & $\begin{array}{c}\text { Concluintes } \\
\text { do EM }\end{array}$ \\
\hline 2000 & 2.648 .638 & 3.305 .837 & 2.532 .744 & 2.079 .629 & 1.836 .130 \\
\hline 2001 & 2.707 .683 & 3.438 .523 & 2.479 .473 & 2.138 .931 & 1.855 .419 \\
\hline 2002 & 2.778 .033 & 3.481 .556 & 2.585 .801 & 2.239 .544 & 1.884 .874 \\
\hline 2003 & 2.668 .605 & 3.687 .333 & 2.736 .381 & 2.213 .370 & 1.851 .834 \\
\hline 2004 & 2.462 .319 & 3.782 .921 & 2.885 .874 & 2.358 .908 & 1.879 .044 \\
\hline 2005 & 2.471 .690 & 3.660 .934 & 2.846 .877 & 2.412 .701 & 1.858 .615 \\
\hline 2006 & 2.174 .398 & 3.651 .903 & 2.772 .967 & 2.385 .919 & 1.848 .415 \\
\hline 2007 & 2.314 .398 & 3.490 .048 & 2.629 .339 & 2.211 .998 & 1.749 .731 \\
\hline 2008 & 2.354 .688 & 3.283 .076 & 2.535 .908 & 2.176 .547 & 1.761 .425 \\
\hline 2009 & 2.473 .073 & 3.430 .376 & 2.574 .195 & 2.218 .830 & 1.797 .434 \\
\hline
\end{tabular}

Fonte: MEC/Inep/Deed, 2010.

É evidente que, no período em análise, a distribuição relativa das matrículas entre as três séries do ensino médio (Tabela 7) revelou uma discreta diminuição da concentração dos registros na $1^{\text {a }}$ série (de 40,3\% em 2000 para 39,9\% em 2002). Com efeito, em termos relativos, as matrículas na $2^{\mathrm{a}}$ e na $3^{\mathrm{a}}$ séries apresentaram maior crescimento. Assim, pelo menos no período considerado, a participação das matrículas possivelmente realizadas por indivíduos em idade própria que já estavam matriculados no ensino médio foi significativa. Por isso mesmo a TML cresceu significativamente: de 34,4\% em 2000 para 40\% em 2002, como se lê na Tabela 5.

Tabela 7 - Distribuição relativa das matrículas por série no ensino médio - 2000-09

\begin{tabular}{|c|c|c|c|}
\hline Ano & $\begin{array}{c}\text { Mat. } \mathbf{1}^{\text {a }} \text { série do EM } \\
\text { (\%) }\end{array}$ & $\begin{array}{c}\text { Mat. } \mathbf{2}^{\text {a }} \text { série do EM } \\
\text { (\%) }\end{array}$ & $\begin{array}{c}\text { Mat. } 3^{\text {a }} \text { série do EM } \\
\text { (\%) }\end{array}$ \\
\hline 2000 & 40,3 & 30,9 & 25,4 \\
\hline 2001 & 40,9 & 29,5 & 25,4 \\
\hline 2002 & 39,9 & 29,6 & 25,7 \\
\hline 2003 & 40,6 & 30,1 & 24,4 \\
\hline 2004 & 41,2 & 31,4 & 25,7 \\
\hline 2005 & 39,3 & 30,6 & 26,3 \\
\hline 2006 & 41,0 & 31,1 & 26,5 \\
\hline 2007 & 41,1 & 31,4 & 26,4 \\
\hline 2008 & 39,6 & 30,6 & 26,9 \\
\hline 2009 & 41,4 & 31,0 & 26,8 \\
\hline
\end{tabular}

Fonte: MEC/Inep/Deed, 2010

Observação: Não foram consideradas as matrículas na $4^{a}$ série do ensino médio e do ensino médio não seriado. 
Entre 2002 e 2004, as matrículas no ensino médio tiveram um incremento relativo de 5,2\%. Chama a atenção o fato de que, entre 2001 e 2003, o número de concluintes do ensino fundamental regular apresentou ligeira queda (menos 3.585). Portanto, também aqui, ao contrário do que se observou na década de 1990, o número de egressos da escolarização obrigatória diminuiu.

É possível, nesse contexto, que o grande número de matrículas de maiores de 14 anos no ensino fundamental nos anos 1990 tenha produzido, anos depois, seus efeitos negativos. Assim, alguns desses jovens simplesmente não teriam condições de prosseguir seus estudos ou, se prosseguiram, não tiveram um adequado aproveitamento. Com efeito, a taxa de reprovação ${ }^{9}$ na $8^{a}$ série do ensino fundamental aumentou significativamente na década de 2000.

Ressalte-se que, no ano de 2006, após longo período de crescimento, as matrículas no ensino médio diminuíram. Entre 2004 e 2006, o decréscimo relativo foi de 3\%. Em 2007, em relação ao ano anterior, a queda foi ainda mais significativa: 7,8\% (menos 0,6 milhão de matrículas). Assim, o processo de ampliação das matrículas no ensino médio iniciado e desenvolvido na década de 1990 apresentou claros sinais de estagnação a partir de meados dos anos 2000.

A análise dos indicadores de matrícula e de escolarização nos anos de 2002 e 2005 (Tabela 5), embora não explique por si o desgaste das matrículas no ensino médio, traz maior clareza à análise. Observa-se que no primeiro ano, para uma população na faixa etária adequada de 10,3 milhões, aproximadamente 8,4 milhões frequentavam algum nível ou modalidade de ensino (TF de 81,5\%); destes, aproximadamente 4,1 milhões cursavam uma série da escolarização média (TML de 40\%). Em 2005, a população de 15 a 17 anos (10,6 milhões de indivíduos) e o número de jovens estudantes nessa faixa etária (aproximadamente 8,69 milhões - TF de 82,2\%) se mantiveram estáveis, ao passo que o número de matrículas na idade própria para o ensino médio cresceu significativamente, alcançando 4,69 milhões de registros. Assim, enquanto a participação relativa e absoluta dos indivíduos de 15 a 17 anos na composição das matrículas cresceu, a respectiva população - e o número de estudantes nesta - não sofreu grandes alterações.

Ora, como durante toda a década a população na faixa etária não sofreu alterações significativas e a TML de indivíduos em idade própria

${ }^{9}$ Segundo informações do MEC/ Inep/Deed, as taxas de reprovação na última série do ensino fundamental nos anos de 2000, 2001, 2003, 2005 e 2007 foram, respectivamente, de 6,9\%, 7,5\%, $9 \%, 10,9 \%$ e $11,7 \%$.

${ }^{10}$ Dados do MEC/Inep/Deed apontam que as taxas de distorção idade-série do ensino médio nos anos de 2007, 2008 e 2009 são, respectivamente, de $44,8 \%$, $40,3 \%$ e $38,1 \%$ na primeira série $41,4 \%, 32,9 \%$ e 32,9 na segunda e $40,6 \%, 31,7 \%$ e $42,5 \%$ na terceira série. aumentou ano a ano (em 2008 a TML era de 50,4\%, contra 34,4\% em 2000), a capacidade do ensino médio de absorver discentes fora da faixa etária parece ter diminuído. Como consequência, a TMB cresceu em ritmo muito menor: de 73\% em 2000 para 85,5\% em 2008.

Nesse contexto, a taxa ${ }^{10}$ de distorção idade-série no ensino médio diminuiu significativamente de 2007 para 2009. A evolução da taxa na $1^{\text {a }}$ série da escolarização secundária (de 44,8\% em 2007 para 38,1\% em 2009) deve ser observada com cuidado: representa, por um lado, que uma quantidade menor de maiores de 15 anos ingressou no ensino médio (o que é, sem dúvida, um avanço) e, por outro, que muitos adolescentes estão "presos" no ensino fundamental. 
O advento da Emenda Constitucional no 59/2009, que prescreveu a obrigatoriedade do ensino médio a partir de 2016 a todos os indivíduos (na idade própria ou não), torna a questão ainda mais relevante, uma vez que os indicadores oficiais recentes evidenciam um longo caminho a ser percorrido com vista à efetivação de tal ditame constitucional. No caso, vale ressaltar, tomados os dados de 2008, que:

- Dos indivíduos na faixa etária de 15 a 17 anos (10,28 milhões), apenas 5,18 milhões estavam matriculados no ensino médio (TML de $50,4 \%)$;

- Tendo em vista que, no mesmo ano, 8,6 milhões dos indivíduos de 15 a 17 anos eram estudantes, há um número significativo de jovens e adolescentes que deveriam estar cursando o ensino médio que ainda não conseguiram vencer as barreiras do ensino fundamental;

- Mais de 1,6 milhão de pessoas em idade apropriada para o ensino médio sequer estão matriculados na escola (em qualquer nível ou modalidade).

\section{Considerações finais}

Não obstante constarem da chamada agenda política social, as decisões governamentais na área educacional sofrem notável influência do modelo político mais amplo vigente no País num determinado momento histórico. É nesse contexto que a universalização do acesso ao ensino fundamental, processo não inteiramente concluído, chamou a atenção, nos últimos anos, do legislador constituinte para a necessidade de ampliação das oportunidades educacionais dos egressos desse nível de ensino.

O processo de universalização do acesso à escola fundamental gerou, pois, o desafio de permitir que os indivíduos que a concluam prossigam nos estudos de modo a ter acesso à cultura e ao conhecimento científico contínua e amplamente produzidos pela humanidade. Em outros termos, a ampliação de oportunidades educacionais na sociedade contemporânea, dita do conhecimento, demanda, paradoxalmente, ampliação de oportunidades educacionais.

Nesse sentido, o número de matrículas no ensino médio, etapa da educação básica subsequente ao ensino fundamental, teve um considerável e inédito avanço nas duas últimas décadas, em que pese o processo de estagnação observado desde 2005.

Entretanto, pouco mais da metade dos indivíduos de 15 a 17 anos encontram-se matriculados nas redes de ensino médio e aproximadamente $15 \%$ sequer estão matriculados no sistema de ensino.

É nesse cenário que a edição da Emenda Constitucional no 59/2009, que consagrou o ensino médio como direito público subjetivo e a progressiva universalidade de seu atendimento até o ano de 2016, impõe a retomada do crescimento das matrículas e a consequente melhoria dos indicadores oficiais de escolarização e matrícula. A demanda por atendimento é grande e o prazo é curto. Democratizar o acesso é, pois, o desafio. 


\section{Referências bibliográficas}

BRASIL. Constituição da República Federativa do Brasil. Atualizada com as emendas constitucionais promulgadas. 1988. Disponível em: < http:// www.planalto.gov.br/ccivil_03/constituicao/constitui\%C3\%A7ao.htm>.

. Lei no 9.394, de 20 de dezembro de 1996. Estabelece as diretrizes e bases da educação nacional. Disponível em: < http://www. planalto.gov.br/ccivil_03/leis/19394.htm>.

Lei no 9.424, de 24 de dezembro de 1996. Dispõe sobre a criação do Fundo de Manutenção e Desenvolvimento do Ensino Fundamental e de Valorização do Magistério. Disponível em: $<$ http://www.planalto.gov.br/ccivil_03/Leis/L9424compilado.htm>.

Lei no 10.172, de 9 de janeiro de 2001. Aprova o Plano Nacional de Educação e dá outras providências Disponível em: <http://www.planalto.gov.br/ccivil_03/Leis/LEIS_2001/L10172.htm>.

Lei no 11.274, de 6 de fevereiro de 2006. Altera a redação dos arts. 29, 30, 32 e 87 da Lei no 9.394, de 20 de dezembro de 1996, que estabelece as diretrizes e bases da educação nacional, dispondo sobre a duração de 9 (nove) anos para o ensino fundamental, com matrícula obrigatória a partir dos 6 (seis) anos de idade. Disponível em: < http://www.planalto.gov.br/ccivil_03/_ Ato2004-2006/2006/Lei/L11274.htm>.

. Lei $n^{\circ} 11.494$, de 20 de junho de 2007. Regulamenta o Fundo de Manutenção e Desenvolvimento da Educação Básica e de Valorização dos Profissionais da Educação - Fundeb [...]. Disponível em: <http://www.planalto.gov.br/ccivil_03/_Ato2007-2010/2007/Lei/ L11494.htm $>$.

CARNEIRO, Moaci Alves. LDB fácil: leitura crítico-compreensiva, artigo a artigo. Petrópolis: Vozes, 2010.

GOMES, Cândido Alberto da Costa. A democratização do ensino médio: ontem e hoje. Caderno SRH, Salvador, n. 34, p. 199-219, jan./jun. 2001.

GOULART, Linda Taranto et al. O desafio de universalização do ensino médio. Brasília: Inep, 2006. Disponível em: < http://www.inep.gov.br/ imprensa/artigos/2006>. Acesso em: 11 ago. 2010.

LIBÂNEO, José Carlos. Educação: políticas, estrutura e organização. São Paulo: Cortez, 2008. 
OLIVEIRA, Romualdo Portela de. Da universalização do ensino fundamental ao desafio da qualidade: uma análise histórica. Educação \& Sociedade, Campinas, v. 28, n. 100, p. 661-690, out. 2007.

OLIVEIRA, Romualdo Portela de; SANTANA, Wagner (Orgs.). Educação e federalismo no Brasil: combater as desigualdades, garantir a diversidade. Brasília: Unesco, 2010.

SAMPAIO, Carlos Eduardo Moreno. Situação educacional dos jovens brasileiros na faixa etária de 15 a 17 anos. Brasília: Inep, 2007. Disponível em: <http://www.publicacoes.inep.gov.br/arquivos>. Acesso em: 6 set. 2010.

SAVIANI, Demerval. Da nova LDB ao Fundeb. Campinas: Autores Associados, 2008.

Leonardo Claver Amorim Lima, mestrando em Educação na Universidade Católica de Brasília (UCB), é especialista em Financiamento e Execução de Programas e Projetos Educacionais do Fundo Nacional de Desenvolvimento da Educação (FNDE).

leonardoclaver@gmail.com

Recebido em 5 de janeiro de 2011.

Aprovado em 9 de junho de 2011. 